02

\title{
Люминесцентные свойства соединений европия(III) с хинальдиновой кислотой и фосфорсодержащими нейтральными лигандами димерного строения
}

\section{(C) И.В. Калиновская}

Институт химии Дальневосточного отделения РАН, 690022 Владивосток, Россия

e-mail: kalinovskaya@ich.dvo.ru

Поступила в редакцию 18.12.2017г.

В окончательной редакции 22.03.2018г.

\begin{abstract}
Синтезированы новые люминесцирующие комплексные разнолигандные соединения европия(III) с хинальдиновой кислотой и фосфорсодержащими нейтральными лигандами димерного строения. Изучено строение, термические и спектрально-люминесцентные свойства комплексных разнолигандных соединений европия(III). Показано, что хинальдинат-ион координируется к иону европия(III) бидентатно. Обнаружено, что передача энергии возбуждения на ион европия(III) осуществляется с уровней хинальдиновой кислоты и фосфорсодержащего нейтрального лиганда.
\end{abstract}

DOI: $10.21883 /$ OS.2018.08.46355.295-17

Значительный научный и практический интерес представляют фотоустойчивые интенсивно люминесцирующие комплексные соединения редкоземельных элементов с карбоксилсодержащими лигандами. Данные комплексные соединения лантаноидов с карбоновыми кислотами успешно используются для получения функциональных оптических материалов для нужд оптоэлектроники и сенсорики [1-6].

Комплексные соединения редкоземельных элементов с обычными карбоновыми кислотами имеют небольшой квантовый выход люминесценции $[7,8]$.

Представителем группы разнолигандных комплексных соединений редкоземельных элементов, имеющих высокий квантовый выход, являются комплексные соединения европия(III) с хинальдиновой кислотой [9]. Хинальдиновая кислота (2-хинолинкарбоновая) имеет сходную структуру с пиридинкарбоновыми кислотами, но более развитую систему сопряженных связей [10].

Наличие двух функциональных групп у хинальдиновой кислоты и возможные различные способы координации карбоксильной группы могут приводить к появлению нескольких рядов разнолигандных хинальдинатов редкоземельных элементов с интересными люминесцентными свойствами. Так, нами были синтезированы комплексные хинальдинаты европия(III) островного, димерного и полимерного строений $[11,12]$. Получить разнолигандные комплексные соединения европия с хинальдиновой кислотой и другими лигандами сложно: из реакционной среды, как правило, кристаллизуется осадок, содержащий несколько комплексных соединений редкоземельных элементов [9].

В продолжение данных исследований в настоящем сообщении представлены результаты изучения термических и спектрально-люминесцентных разнолигандных комплексных соединений европия(III) с хинальдиновой кислотой и фосфорсодержащими ней- тральными лигандами димерного строения состава $\left[\mathrm{Eu}_{2}(\text { Quin })_{4} 2 \mathrm{H}_{2} \mathrm{OD}\right]_{2}\left(\mathrm{NO}_{3}\right)_{2} \mathrm{H}_{2} \mathrm{O}$, где Quin - анион хинальдиновой кислоты, D - трифенилфосфиноксид (tppo), гексаметилфосфотриамид (hmpa) или гексаэтилфосфотриамид $\left(\mathrm{Et}_{6} \mathrm{pa}\right)$.

\section{Экспериментальная часть}

Для синтеза разнолигандных комплексных соединений состава $\left[\mathrm{Eu}_{2}(\mathrm{Quin})_{4} 2 \mathrm{H}_{2} \mathrm{OD}\right]_{2}\left(\mathrm{NO}_{3}\right)_{2} \mathrm{H}_{2} \mathrm{O}$ использовали следующие реактивы марки „ч“: шестиводный нитрат европия(III), хинальдиновую кислоту, фосфорсодержащие лиганды (трифенилфосфиноксид, гексаметилфосфотриамид, гексаэтилфосфотриамид). Хинальдиновую кислоту перекристаллизовывали из 96\% этанола. Разнолигандные комплексные соединения с хинальдиновой кислотой и фосфорсодержащими нейтральными лигандами димерного строения получали по следующей методике: к водному раствору нитрата европия(III) приливали этанольный раствор хинальдиновой кислоты и фосфорсодержащего нейтрального лиганда в мольном отношении $1: 2: 1$. 10\%-м раствором аммиака доводили $\mathrm{pH}$ до 5.5-6.0 и оставляли стоять до образования осадка. Осадок отфильтровывали, промывали водно-этанольной смесью, сушили на воздухе.

Синтезированные комплексные соединения европия(III) представляют собой мелкокристаллические порошки желтого цвета, растворимые в полярных растворителях. Термограммы соединений получены на дериватографе системы Паулик, Паулик и Эрдей. Скорость нагрева $5 \mathrm{grad} / \mathrm{min}$ (в качестве эталона использовали $\left.\alpha-\mathrm{Al}_{2} \mathrm{O}_{3}\right)$.

Электронные спектры поглощения регистрировали на спектрометре RF-2550 Shimadzu, а спектры возбуждения люминесценции и спектры люминесценции - на прибоpe RF-5301 Shimadzu. 
Таблица 1. Данные химического элементного анализа для хинальдинатов европия(III) с фосфорсодержащими нейтральными лигандами димерного строения

\begin{tabular}{c|c|c|c|c|c|c|c|c|c|c}
\hline \multirow{2}{*}{ Соединение } & \multicolumn{4}{|c|}{ Найдено, \% } & \multicolumn{4}{c}{ Вычислено, \% } \\
\cline { 2 - 10 } & $\mathrm{C}$ & $\mathrm{H}$ & $\mathrm{N}$ & $\mathrm{H}_{2} \mathrm{O}$ & $\mathrm{Eu}$ & $\mathrm{C}$ & $\mathrm{H}$ & $\mathrm{N}$ & $\mathrm{H} 2 \mathrm{O}$ & $\mathrm{Eu}$ \\
\hline$\left[\mathrm{Eu}_{2}(\text { Quin })_{4} 2 \mathrm{H}_{2} \mathrm{O} 2 \mathrm{tppo}\right]_{2}\left(\mathrm{NO}_{3}\right)_{2} \mathrm{H}_{2} \mathrm{O}$ & 52.9 & 3.3 & 4.8 & 3.5 & 17.9 & 52.8 & 3.5 & 4.9 & 3.1 & 17.6 \\
{$\left[\mathrm{Eu}_{2}(\text { Quin })_{4} 2 \mathrm{H}_{2} \mathrm{O} 2 \mathrm{hmpa}\right]_{2}\left(\mathrm{NO}_{3}\right)_{2} \mathrm{H}_{2} \mathrm{O}$} & 41.1 & 4.1 & 9.0 & 3.4 & 20.1 & 40.8 & 4.3 & 8.6 & 3.5 & 19.9 \\
{$\left[\mathrm{Eu}_{2}(\text { Quin })_{4} 2 \mathrm{H}_{2} \mathrm{O} 2 \mathrm{Et}_{6} \mathrm{pa}\right]_{2}\left(\mathrm{NO}_{3}\right)_{2} \mathrm{H}_{2} \mathrm{O}$} & 45.6 & 5.5 & 6.4 & 2.9 & 18.1 & 45.3 & 5.3 & 6.6 & 3.2 & 17.9
\end{tabular}

Элементным анализом установлено содержание С и Н в синтезированных комплексных соединениях европия(III), содержание азота определяли методом Дюма, содержание воды - титрованием по Фишеру (табл. 1).

По данным элементного химического анализа состав синтезированных комплексных соединений европия(III) отвечает формуле $\left[\mathrm{Eu}_{2}(\text { Quin })_{4} 2 \mathrm{H}_{2} \mathrm{OD}\right]_{2}\left(\mathrm{NO}_{3}\right)_{2} \mathrm{H}_{2} \mathrm{O}$, где $\mathrm{D}$ - фосфорсодержащий нейтральный лиганд (tppo, hmpa, $\mathrm{Et}_{6}$ pa).

\section{Результаты и их обсуждение}

Синтезированные разнолигандные комплексные соединения европия(III) не разлагаются при длительном хранении, устойчивы на воздухе. При нагревании все полученные комплексные соединения разлагаются. Для определения гидратного состава, получения данных о дегидратации, составе и разложении разнолигандных комплексных хинальдинатов европия(III) проведен их термогравиметрический анализ в интервале температур $25-700^{\circ} \mathrm{C}$. Характер разложения комплексных соединений европия(III) однотипен.

Разложение хинальдинатов европия(III) димерного строения с фосфорсодержащими нейтральными лигандами происходит аналогично разложению комплексных соединений с азотсодержащими нейтральными лигандами [9]. Термолиз комплексных соединений осуществляется в три стадии. Область температур $90-130^{\circ} \mathrm{C}$ соответствует процессу дегидратации комплексных хинальдинатов европия(III), протекающему в одну стадию с эндотермическим эффектом (табл. 2). Содержание воды, вычисленное по убыли веса образца, соответствует расчетному. Отщепление нейтральных лигандов протекает в одну стадию в интервале $135-270^{\circ} \mathrm{C}$. На кривых TG и DTG этому процессу соответствуют эндотермический эффект с минимумами при $220-240^{\circ} \mathrm{C}$. На конец отщепления нейтрального лиганда накладывается процесс разложения разнолигандных комплексных соединений европия(III), поэтому невозможно получить безводный хинальдинат европия(III). Интенсивная деструкция полученных соединений, связанная с образованием оксида европия(III), наблюдается в интервале температур $400-600^{\circ} \mathrm{C}$.

Наибольшей термической устойчивостью из синтезированных разнолигандных соединений обладает хи-
Таблица 2. Результаты термогравиметрического анализа хинальдинатов европия(III) с фосфорсодержащими нейтральными лигандами димерного строения

\begin{tabular}{c|c|c|c}
\hline \multicolumn{2}{c|}{ Соединения } & 1-я стадия & 2-я стадия \\
\hline$\left[\mathrm{Eu}_{2}(\text { Quin })_{4} 2 \mathrm{H}_{2} \mathrm{O} 2 \mathrm{tppo}\right]_{2}$ & $T,{ }^{\circ} \mathrm{C}$ & $110-120$ & $125-260$ \\
$\left(\mathrm{NO}_{3}\right)_{2} \mathrm{H}_{2} \mathrm{O}$ & $\Delta m, \%$ & 3.2 & 32.2 \\
{$\left[\mathrm{Eu}_{2}(\mathrm{Quin})_{4} 2 \mathrm{H}_{2} \mathrm{O} 2 \mathrm{hmpa}\right]_{2}$} & $T,{ }^{\circ} \mathrm{C}$ & $90-120$ & $125-270$ \\
$\left(\mathrm{NO}_{3}\right)_{2} \mathrm{H}_{2} \mathrm{O}$ & $\Delta m, \%$ & 3.5 & 23.5 \\
{$\left[\mathrm{Eu}_{2}(\mathrm{Quin})_{4} 2 \mathrm{H}_{2} \mathrm{O} 2 \mathrm{Et}_{6} \mathrm{pa}\right]_{2}$} & $T,{ }^{\circ} \mathrm{C}$ & $100-120$ & $125-275$ \\
$\left(\mathrm{NO}_{3}\right)_{2} \mathrm{H}_{2} \mathrm{O}$ & $\Delta m, \%$ & 3.2 & 31.0
\end{tabular}

нальдинат европия(III) с трифенилфосфиноксидом. Термическая устойчивость исследуемых комплексных соединений европия(III) ниже термической устойчивости хинальдинатов европия(III) полимерного строения [12] и сравнима с термической устойчивостью хинальдинатов европия(III) с азотсодержащими нейтральными лигандами димерного строения [11]. По-видимому, наличие связи иона европия(III) с двумя функциональными группами в случае комплексных соединений полимерного строения [12] существенно повышает термическую устойчивость комплексных соединений европия(III).

ИК спектры полученных хинальдинатов европия(III) изучались нами в интервале частот $400-3200 \mathrm{~cm}^{-1}$.

На наличие депротонированной карбоксильной группы в комплексных соединениях указывает исчезновение полосы деформационного колебания ОН-группы при $990 \mathrm{~cm}^{-1}$ [13]. Поглощение карбонильной группы „свободной“ хинальдиновой кислоты при $1705 \mathrm{~cm}^{-1}$ в спектрах хинальдинатов европия(III) отсутствует [13]. Интенсивные полосы при 800-807, 1620-1630 и $1375-1385 \mathrm{~cm}^{-1}$ относятся соответственно к колебаниям $\delta\left(\mathrm{OCO}^{-}\right), \gamma_{a s}\left(\mathrm{COO}^{-}\right), \gamma_{s}\left(\mathrm{COO}^{-}\right)$бидентатно связанных карбоксильных групп, а поглощение меньшей интенсивности при 1468-1469 и $1563-1569 \mathrm{~cm}^{-1}$ может быть обусловлено валентными колебаниями связей $\mathrm{C}-\mathrm{C}$ и $\mathrm{C}-\mathrm{N}[14,15]$. Подобные полосы поглощения найдены в ИК спектрах комплексных хинальдинатов европия(III) островного строения. В работе [11] на основании данных ИК и рентгеноэлектронных спектров установлено, что хинальдиновая кислота в комплексных хинальдинатах европия(III) островного строения координируется бидентатно. В ИК спектре синтезированных комплексных соединений европия интенсивно проявляются 


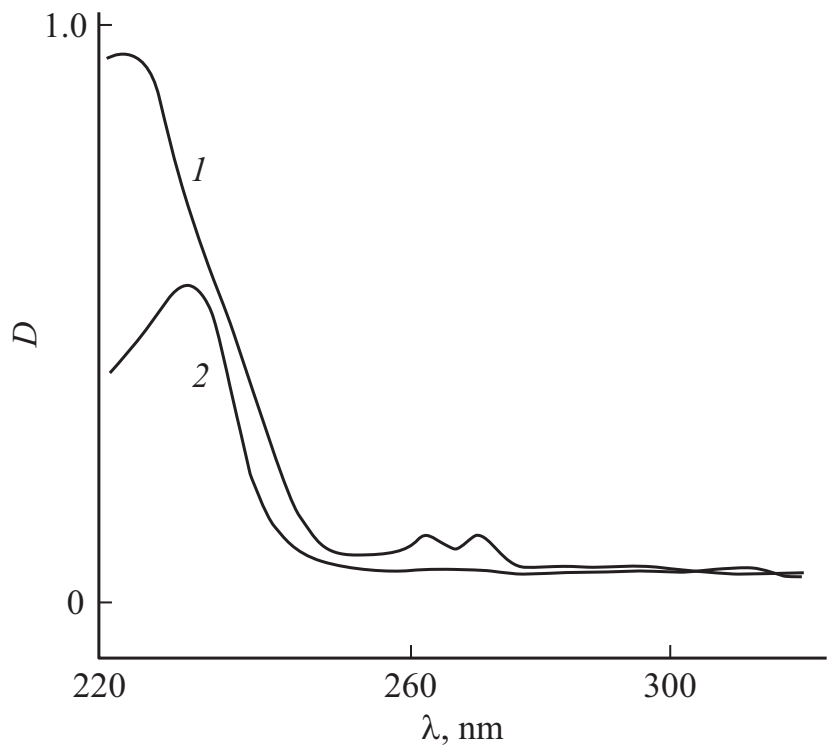

Рис. 1. Электронные спектры поглощения: 1 $\left[\mathrm{Eu}_{2} \text { (Quin) }\right)_{4} 2 \mathrm{H}_{2} \mathrm{O} 2$ tppo $]_{2}\left(\mathrm{NO}_{3}\right)_{2} \mathrm{H}_{2} \mathrm{O}, 2-\mathrm{HQuin}$.

симметричные колебания карбоксильной группы кислоты в областях $1375-1385,680-690 \mathrm{~cm}^{-1}$. Проявление этих колебаний также свидетельствует о существовании бидентатной координации карбоксильной группы [15]. Разность частот $\Delta v=v_{a s}\left(\mathrm{COO}^{-}\right)-v_{s}\left(\mathrm{COO}^{-}\right)$ больше $200 \mathrm{~cm}^{-1}$, что указывает на ионный характер связи $\mathrm{Eu}-\mathrm{O}$ карбоксильной группы хинальдиновой кислоты [11]. Значение $\Delta v>100 \mathrm{~cm}^{-1}$ свидетельствует о бидентатной координации группы $\mathrm{COO}^{-}$ионом европия(III) [13]. Частоты $v(\mathrm{Eu}-\mathrm{N}), v(\mathrm{Eu}-\mathrm{O})$ лежат в синтезированных комплексах ниже $400 \mathrm{~cm}^{-1}$ [10]. В спектре исследуемых комплексных соединений наблюдаются полосы поглощения при $3300-3500 \mathrm{~cm}^{-1}$ в области валентных колебаний воды [14].

Электронный спектр поглощения хинальдината европия(III) с трифенилфосфиноксидом димерного строения представлен на рис. 1. При аддуктообразовнии в спектрах поглощения хинальдиновой кислоты добавились полосы поглощения, соответствующие $\pi-\pi^{*}$-переходам аддуктообразующих агентов (нейтральных молекул) tppo, hmpa, Et 6 pa. Следует отметить, что, так же как и для хинальдиновой кислоты, положение и форма полос поглощения нейтральных фосфорсодержащих молекул практически не меняется при комплексообразовании. Максимум широкой полосы с $\lambda_{\max }=290 \mathrm{~nm}$ в UV-спектрах разнолигандных хинальдинатов европия(III) несколько сдвинут в более длинноволновую область по отношению к максимуму данной полосы в спектре „свободной“ хинальдиновой кислоты. В спектрах поглощения разнолигандных соединений проявляются полосы поглощения нейтральных фосфорсодержащих лигандов с $\lambda_{\max }=266,278 \mathrm{~nm}$ (рис. 1).

Спектры возбуждения люминесценции полученных комплексных соединений европия(III) совпадают со спектрами возбуждения гидрата европия(III) с хиналь- диновой кислотой и нитратом европия(III) с трифенилфосфиноксидом, что свидетельствует об эффективном внутримолекулярном переносе энергии с уровней хинальдиновой кислоты и фосфорсодержащих нейтральных лигандов на ион европия(III). Также в спектре возбуждения люминесценции комплексного соединения проявляются полосы, обусловленные внутриконфигурационными $f-f$-переходами в ионе европия(III).

Полученные разнолигандные комплексные соединения европия(III) (аналогично разнолигандным комплексным соединениям европия(III) с хинальдиновой кислотой островного строения [12]) уже при комнатной температуре обладают интенсивной люминесценцией красного цвета с максимумом люминесценции при $612 \mathrm{~nm}$ (рис. 2). В спектрах люминесценции синтезированных хинальдинатов европия(III) с фосфорсодержащими нейтральными лигандами наиболее интенсивны полосы, относящиеся к электродипольному ${ }^{5} D_{0}-{ }^{7} F_{2}$-переходу. Интенсивность полос, соответствующих триплетному магнитнодипольному ${ }^{5} D_{0}-{ }^{7} F_{1}$-переходу, в 3-4 раза ниже интенсивности полос электродипольного ${ }^{5} D_{0}-{ }^{7} F_{2}$-перехода. Как и для большинства комплексных соединений европия(III), интенсивность линии запрещенного ${ }^{5} D_{0}-{ }^{7} F_{0}$-перехода незначительна. Причем относительная интенсивность линии электродипольного ${ }^{5} D_{0}-{ }^{7} F_{0}$-перехода увеличивается от

$\left.\left[\mathrm{Eu}_{2} \text { (Quin) }\right)_{4} 2 \mathrm{H}_{2} \mathrm{O} 2 \mathrm{hmpa}\right]_{2}\left(\mathrm{NO}_{3}\right)_{2} \mathrm{H}_{2} \mathrm{O}$ к

$\left[\mathrm{Eu}_{2}(\mathrm{Quin})_{4} 2 \mathrm{H}_{2} \mathrm{O} 2 \mathrm{tppo}\right]_{2}\left(\mathrm{NO}_{3}\right)_{2} \mathrm{H}_{2} \mathrm{O}$ и

$\left[\mathrm{Eu}_{2}(\text { Quin })_{4} 2 \mathrm{H}_{2} \mathrm{O} 2 \mathrm{Et}_{6} \mathrm{pa}\right]_{2}\left(\mathrm{NO}_{3}\right)_{2} \mathrm{H}_{2} \mathrm{O}$.

Одной из причин этого может быть увеличение искажения координационного полиэдра комплексного соединения европия при аддуктообразовании. Общий характер

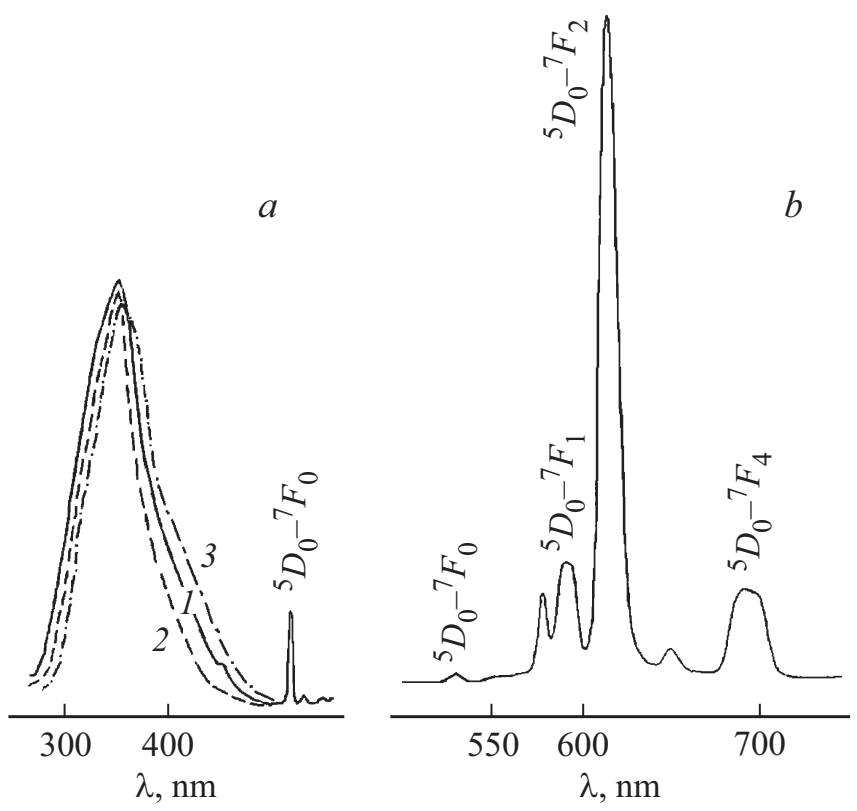

Рис. 2. Спектры возбуждения люминесценции. $a$ : 1 $\left[\mathrm{Eu}_{2} \text { (Quin }\right)_{4} 2 \mathrm{H}_{2} \mathrm{O} 2$ tppo $]_{2}\left(\mathrm{NO}_{3}\right)_{2} \mathrm{H}_{2} \mathrm{O}, 2-\mathrm{Eu}\left(\mathrm{NO}_{3}\right)_{3} 2$ tppo, $3-$ $\mathrm{Eu}$ (Quin) $)_{3} 3 \mathrm{H}_{2} \mathrm{O} \quad\left(\lambda_{\text {reg }}=615 \mathrm{~nm}\right) ; \quad b$ : спектр люминесценции $(77 \mathrm{~K}):\left[\mathrm{Eu}_{2}(\text { Quin })_{4} 2 \mathrm{H}_{2} \mathrm{O} 2 \mathrm{tppo}\right]_{2}\left(\mathrm{NO}_{3}\right)_{2} \mathrm{H}_{2} \mathrm{O}\left(\lambda_{\mathrm{ex}}=365 \mathrm{~nm}\right)$. 
спектров люминесценции по исследуемому ряду соединений европия с хинальдиновой кислотой сохраняется. Однако при замене фосфорсодержащего нейтрального лиганда происходит существенное перераспределение интенсивностей отдельных линий ${ }^{5} D_{0}-{ }^{7} F_{1,2}$-переходов. Повышение донорных свойств нейтрального лиганда в ряду $\left[\mathrm{Eu}_{2}(\mathrm{Quin})_{4} 2 \mathrm{H}_{2} \mathrm{O} 2 \mathrm{Et}_{6} \mathrm{pa}\right]_{2}\left(\mathrm{NO}_{3}\right)_{2} \mathrm{H}_{2} \mathrm{O}$, $\left.\left[\mathrm{Eu}_{2} \text { (Quin) }\right)_{4} 2 \mathrm{H}_{2} \mathrm{O} 2 \mathrm{hmpa}\right]_{2}\left(\mathrm{NO}_{3}\right)_{2} \mathrm{H}_{2} \mathrm{O}, \quad\left[\mathrm{Eu}_{2}(\text { Quin })_{4} 2 \mathrm{H}_{2} \mathrm{O}\right.$ $2 \mathrm{tppo}]_{2}\left(\mathrm{NO}_{3}\right)_{2} \mathrm{H}_{2} \mathrm{O}$ оказывает влияние на величину энергетического зазора резонансного ${ }^{5} D_{0}-{ }^{7} F_{0}$-перехода (смещение 0-0-полосы в красную область), а также приводит к уменьшению величины расщепления штарковских компонент терма ${ }^{7} F_{1},\left(\Delta F_{1}\right)$. Наибольшей интенсивностью люминесценции в данном ряду соединений обладает комплекс $\left.\left[\mathrm{Eu}_{2} \text { (Quin }\right)_{4} 2 \mathrm{H}_{2} \mathrm{O} 2 \mathrm{tppo}\right]_{2}\left(\mathrm{NO}_{3}\right)_{2} \mathrm{H}_{2} \mathrm{O}$.

Таким образом, синтезированы люминесцирующие комплексные соединения европия(III) с хинальдиновой кислотой и фосфорсодержащими нейтральными лигандами димерного строения. Показано, что при термолизе отрыв молекулы воды и нейтрального лиганда происходит в две стадии с эндотермическими эффектами. Обнаружено, что наибольшей термической устойчивостью в изучаемом ряду обладает хинальдинат европия(III) с 1,10-фенантролином. Установлено, что хинальдинат-ион координируется к иону европия(III) бидентатно. Повышение донорных свойств нейтрального лиганда в ряду $\left.\left[\mathrm{Eu}_{2} \text { (Quin) }\right)_{4} 2 \mathrm{H}_{2} \mathrm{O} 2 \mathrm{Et}_{6} \mathrm{pa}\right]_{2}\left(\mathrm{NO}_{3}\right)_{2} \mathrm{H}_{2} \mathrm{O}, \quad\left[\mathrm{Eu}_{2}(\text { Quin })_{4} 2 \mathrm{H}_{2} \mathrm{O}\right.$ $2 \mathrm{hmpa}]_{2}\left(\mathrm{NO}_{3}\right)_{2} \mathrm{H}_{2} \mathrm{O}$, [Eu $\mathrm{Eu}_{2}$ (Quin $\left.)_{4} 2 \mathrm{H}_{2} \mathrm{O} 2 \mathrm{tppo}\right]_{2}\left(\mathrm{NO}_{3}\right)_{2} \mathrm{H}_{2} \mathrm{O}$ оказывает влияние на величину энергетического зазора резонансного ${ }^{5} D_{0}-{ }^{7} F_{0}$-перехода (смещение $0-0$-полосы в красную область), а также приводит к уменьшению величины расщепления штарковских компонент терма ${ }^{7} F_{1},\left(\Delta F_{1}\right)$.

\section{Список литературы}

[1] Kataoka H., Kitano T., Takizawa T., Hirai Y., Nakanishi T., Hasegawa Y. // J. Alloys Compd. 2014. V. 601. P. 293.

[2] Zhang J., Wang R., Bai J., Wang S. // J. Rare Earths. 2002. V. 20. N 5. P. 449.

[3] Zhang J., Wang R., Yang H. // Chin. J. Anal. Chem. 2003. V. 31. N 4. P. 472.

[4] Hasegawa Y., Nakanishi T. // RSC. Adv. 2015. V. 5. P. 338.

[5] Bunzli J.-C.G., Eliseeva S.V. // Chem. Sci. 2013. V. 4. N 5. P. 1913.

[6] Binnemans $K$. Rare-earth Beta-diketonates. Handbook on the Physics and Chemistry of Rare Earths. Elsevier, 2005. V. 35. P. 107-272.

[7] Zolin V.F. // J. Alloys Compd. 2004. V. 380. N 1-2. P. 101.

[8] Петроченкова Н.В., Петухова Н.В., Мирочник А.Г., Карасев В.Е., Либар Л.И. // Коорд. химия. 2001. Т. 27. № 10. C. 790.

[9] Seminara A., Musumeci A. // J. Inorg. Chem. 1977. V. 39. N 4. P. 599.

[10] Zolin V., Puntus L., Kudryashova V.V., Tsaryuk V., Legendziewicz J., Gawryszewska P., Szostak R. // J. Alloys. Compd. 2002. V. 341. P. 376.
[11] Карасев В.Е., Калиновская И.В., Мирочник А.Г., Зайцева Н.Н., Зиатдинов А.М. // Журн. неорган. химии. 1989. T. 34. № 3. C. 618.

[12] Карасев В.Е., Калиновская И.В., Зайцева Н.Н., Лифар Л.И. // Журн. неорган. химии. 1987. Т. 32. № 4. С. 910.

[13] Накамото К. Инфракрасные спектры неорганических и координационных соединений. М.: Мир, 1991. 536 с.

[14] Иогансен А.В., Куркчи Г.А., Дементьева Л.А. // Журн. структ. химии. 1977. Т. 18. № 4. С. 743.

[15] Задорожная А.Н., Калиновская И.В., Карасев В.Е., Шапкин Н.П. // Коорд. химия. 2001. Т. 27. № 7. С. 555. 